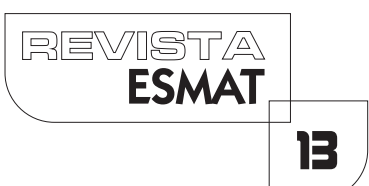

\title{
JUSTIÇA SOCIAL E AS PESSOAS COM DEFICIÊNCIA: DA ABORDAGEM DAS CAPACIDADES AO MODELO SOCIAL
}

SOCIAL JUSTICE AND DISABLED PEOPLE: FROM THE HABILITIES'

APPROACH TO THE SOCIAL MODEL

Eduardo Freitas Horácio da Silva

Mestrando do Programa de Pós Graduação Stricto Sensu em Direito da Universidade do Estado do Rio de Janeiro (UERJ). Advogado. E-mail: efhoracio@gmail.com

\section{RESUMO}

Este artigo pretende expor, ainda que sucintamente, sobre a mudança de paradigmas na percepção da pessoa com deficiência na sociedade. Como referencial teórico, apontase a abordagem das capacidades de Martha Nussbaum. Nesse contexto, examina-se o enfoque das capacidades em comparação com o modelo social de deficiência. Primeiro, aponta-se a mudança na percepção de deficiência nos últimos anos. Posteriormente, discorre-se sobre a teoria de Nussbaum. Ao final, faz-se menção sobre os Direitos Fundamentais das pessoas com deficiência, para demonstrar o diálogo entre a abordagem das capacidades e o modelo social.

PALAVRAS-CHAVE: Justiça Social; Pessoas com Deficiência; Modelo Social.

\section{ABSTRACT}

This article intends to talk about, although briefly, about the paradigms shift in the disabled people's perception inside society. As a theoretical referential, it will show Martha Nussbaum's approach on habilities. In this context, it will examine the focus on habilities comparing them with the social model of disability. For first, it will show the changes on the perception of disability in the last years. Afterwards, it will talk about Nussbaum's theory. At the end, it mentions the disabled people's Fundamental Rights, to show the dialogue between the habilities' approach and the social model.

KEYWORDS: Social Justice; Disabled People; Social Model. 


\section{INTRODUÇÃO}

De acordo com o relatório mundial sobre deficiência, elaborado pela Organização Mundial de Saúde (OMS) e pelo Banco Mundial, mais de um bilhão de pessoas em todo o mundo convivem com alguma forma de deficiência, dentre os quais cerca de 200 milhões experimentam dificuldades funcionais consideráveis, o que corresponde a I $5 \%$ da população mundial (ONU, 20 I I, p. 269). No Brasil, 6,2\% da população apresenta algum tipo de deficiência: intelectual, física, auditiva e visual (IBGE, 20I3, p. 24). São números expressivos, para um grupo de pessoas que, durante muito tempo, foram marginalizadas pela sociedade.

No decorrer da história, a deficiência foi vista pelos mais diversos enfoques. Inicialmente, sob o aspecto da prescindência, que olhava as pessoas com deficiência de forma marginal, pois seriam inúteis para a construção da sociedade. Em seguida, esse grupo foi destinatário do assistencialismo.

Posteriormente, a deficiência passou a ser tratada sob um viés reabilitador, cuja premissa era proporcionar ao sujeito um tratamento médico, visto que as pessoas com deficiência eram consideradas estranhas aos padrões de normalidade vigentes, e, em razão dessa condição de "anormalidade", também sofreram os efeitos de uma completa exclusão social, política e civil. Sua participação, enquanto sujeito de direitos, nas relações jurídicas, em geral, era praticamente nula.

Após a Segunda Guerra Mundial, em razão da mudança do conceito de deficiência, a pessoa com deficiência passa a ser vinculada ao catálogo de direitos da personalidade, que são garantidos pela simples existência do sujeito. Logo, sendo a personalidade atributo inerente ao homem, é essa que lhe alça ao status de sujeito de direitos e obrigações.

Posteriormente, há mudança na abordagem da deficiência, que passa a adotar o modelo social, alçando a deficiência como uma questão de direitos humanos. Tal fato impõe novo significado ao conceito de deficiência, que passa a ser definido como uma interação do corpo com impedimentos e barreiras impostas pela sociedade. E promove, ao mesmo tempo, um tratamento pautado na convivência familiar e na inclusão comunitária.

É nesse contexto que documentos internacionais foram promulgados com o intuito de garantir a plenitude de direito das pessoas com deficiência. Destaca-se a Convenção sobre os Direitos da Pessoa com Deficiência (CPCD)', que inova ao assegurar o pleno exercício de todos os direitos humanos e liberdades fundamentais por esses indivíduos.

' A Convenção sobre os Direitos da Pessoa com Deficiência, foi aprovada no Brasil pelo Decreto Legislativo $n^{\circ} \mid 86$, de 2008 , conforme o procedimento previsto no $\S 3^{\circ}$ do art. $5^{\circ}$ da Constituição Federal, e, em seguida, promulgada pelo Decreto $n^{\circ}$ 6.949, de 2009. Assim, a referida Convenção foi incorporada no ordenamento jurídico pátrio com status de emenda constitucional. 
A partir dessa Convenção, não há mais presunção de incapacidade de agir da pessoa com deficiência, que passa a ser dotada de capacidade de exercício, ou seja, além de gozar de direitos, poderá exercê-los pessoalmente, sem a intervenção de terceiros.

\section{A MUDANÇA DE PARADIGMA: DA MARGINALIZAÇÃO À TUTELA DA PESSOA COMDEFICIÊNCIA}

A marginalização das pessoas, cujas características destoam dos padrões considerados normais, no decorrer da história, encontra sua legitimação na fixação de certas espécies de habilidades ajustadas para o convívio social, conquanto a mudança da percepção das pessoas com deficiência no decurso dos últimos anos demonstrasse um momento de valorização das diferenças, ante a estabilização de modelos de Direitos Humanos ensejadores de políticas públicas.

Até então, foram várias as concepções da dignidade humana no mundo ocidental, que passou de uma concepção religiosa, fundamentada num predicado advindo da imagem divina, para ser percebida por meio da liberdade humana, como bem pontua Ana Paula Barbosa-Fohrmann:

Até o século XIX, surgiram várias concepções da dignidade humana no Ocidente. A primeira foi a concepção religiosa que dominou a Idade Média e, de acordo com a qual, a dignidade humana se basearia num atributo decorrente da imagem de Deus. Em segundo lugar, apareceram as concepções modernas, como as de P. dela Mirandola, S. Pufendorf e I. Kant. A dignidade do homem se distanciou da ideia da imagem de Deus. $O$ indivíduo obteve um posicionamento especial. Ele passou a se encontrar, como totalidade, no centro do mundo. Nesse sentido, seu posicionamento foi comparado ao de Deus. A dignidade passou a ser justificada com base na liberdade humana e na autodeterminação (P. dela Mirandola). A dignidade seria parte da natureza humana e só seria reconhecida e respeitada no convívio social (S. Pufendorf). No lluminismo, a dignidade incorporou uma feição moral e liberal. Só homens racionais, que se submetessem moralmente e por livre arbítrio à lei, possuiriam dignidade. Pelo fato de o homem ser digno, não poderia ser tratado como mero objeto, mas como uma totalidade insubstituível (I. Kant). Segundo a concepção socialista do Século XIX, a dignidade se identificou com a justiça e o trabalho. $\bigcirc$ homem poderia vir a perdê-la, caso viesse a viver em uma sociedade que não assegurasse os pressupostos de uma vida digna. (20 I 2, p. 9-10).

A partir da consideração da ideia de direitos humanos como valor relevante, após as atrocidades cometidas durante a $2^{\mathrm{a}}$ Guerra Mundial, a comunidade internacional passou 
a reconhecer que a proteção dos direitos humanos constituía uma questão de legítimo interesse e preocupação internacional. Logo, os direitos humanos acabam por transcender e extrapolar o domínio reservado do Estado ou a competência nacional exclusiva. Em razão disso, é criado um código comum de ação composto por parâmetros globais de ação estatal, ao qual deve haver a conformação dos Estados, no que diz respeito à promoção e proteção dos direitos humanos (PIOVESAN, 2006b, p. 5).

Com a promulgação da Declaração Universal dos Direitos do Homem (ASSEMBLEIA, 1948), e a sua reiteração pela Declaração de Direitos Humanos (CONFERÊNCIA, 1993), há uma reaproximação dos fundamentos dos direitos humanos com o pensamento kantiano, com as ideias de moralidade, dignidade e paz perpétua. Pela Declaração, de 1948, os direitos humanos são caracterizados pela universalidade e indivisibilidade. Justifica-se a universalidade pela condição de pessoa ser o único requisito exigido para a titularidade de direitos, uma vez que o ser humano é essencialmente moral, dotado de unicidade existencial e dignidade, inerente à condição humana. Indivisibilidade porque os direitos humanos compõem uma unidade indivisível e interdependente, conjugando os direitos civis e políticos com os direitos econômicos, sociais e culturais (PIOVESAN, 2006a, p. 5).

Entretanto, para que tais direitos alcançassem consequência universal foi necessária a internacionalização do discurso dos direitos humanos, para assegurar a todos o direito a ter direitos (SARLET, 2004, p. 52-53). E ainda, somente a partir do pós-guerra é que podemos falar em movimento de internacionalização dos direitos humanos, como será a seguir demonstrado.

Com a atuação dos organismos internacionais, as violações aos direitos humanos ganham maior visibilidade. $\bigcirc$ Estado infrator, sob o risco de sofrer constrangimento político e moral, vê-se obrigado a justificar suas omissões e desrespeitos a esses direitos, o que acaba desencadeando a modificação ou melhoria de certas políticas públicas, ocasionando suporte ou estímulo para alterações internas (ROSATO; CORREIA, 2012 , p. 94).

Nesse enredo, irrompem-se vários documentos internacionais com o intuito de garantir e proteger os direitos humanos dos grupos historicamente vulneráveis, como negros, mulheres, crianças, idosos e pessoas com deficiência. A exemplo, destaca-se a Convenção sobre a Eliminação de Todas as Formas de Discriminação contra a Mulher (ASSEMBLEIA, 1979), a Convenção sobre os Direitos das Crianças (ASSEMBLEIA, 1989), dentre outros.

Por sua vez, a Convenção sobre os Direitos da Pessoa com Deficiência apresenta-se como um marco na inclusão social e defesa dos direitos das pessoas em sofrimento psíquico. Aprovada pela Assembleia Geral da Organização das Nações Unidas (ONU), em 13 de dezembro de 2006, nos termos da Resolução da Assembleia Geral n 61/106, tem como propósito "promover, proteger e assegurar o exercício pleno e equitativo de todos os direitos humanos e liberdades fundamentais por todas as pessoas 
com deficiência e promover o respeito a sua dignidade inerente".

A principal mudança advinda com a Convenção sobre os Direitos da Pessoa com Deficiência é o apontamento para os Estados signatários do dever de remover e eliminar os obstáculos que impeçam o exercício de direitos da pessoa com deficiência. Assim, compete a esses Estados viabilizar o pleno desenvolvimento das potencialidades, autonomia e participação desses sujeitos. A Convenção sobre os Direitos da Pessoa com Deficiência introduz o conceito de reasonable accommodation, ${ }^{2}$ ou seja, determina que os Estados signatários devam adotar ajustes, adaptações, ou modificações razoáveis para assegurar à pessoa com deficiência o exercício de direitos humanos em igualdade de condições com os demais. Caso haja contrariamente ao preceito da adaptação razoável, estaria o Estado disseminando a descriminação tanto na esfera pública quanto na esfera privada (PIOVESAN, 2012, p. 292). Nesse contexto, os estados signatários devem adequar a legislação interna e promover políticas de inclusão, a fim de que as pessoas com deficiência possam gozar e exercer os direitos prescritos na Convenção.

\section{O ENFOQUE DAS CAPACIDADES DE NUSSBAUM}

A abordagem das capacidades de Nussbaum é uma alternativa ao modelo utilitarista, que iguala a qualidade de vida ao crescimento do PIB, acaba por negligenciar a distribuição de riquezas, dissimulando as desigualdades (NUSBAUMM, 20 I3, p. 348350), por desconsiderar fatores intrínsecos à qualidade de vida que não estão relacionados à renda, mas indispensáveis ao desenvolvimento humano, como: a saúde, a educação, dentre outros (SEN, 20 I I , p. 259).

Esse pensamento fundamentou o desenvolvimento da abordagem das capacidades, como um novo modelo de análise da qualidade de vida e do nível de justiça promovido pelas sociedades aos seus cidadãos (NUSBAUMM, 20 I3, p. 89).

Voltada à vida humana, a abordagem das capacidades muda o foco de atenção para as oportunidades reais da vida (SEN, 20 I I , p. 275), uma vez que o desenvolvimento de uma pessoa somente se torna possível com a criação das condições necessárias à liberdade de escolha desta, para dar forma à sua própria vida. Nesse contexto, as capacidades seriam liberdades substantivas (SEN, 201 I, p. 275), ou seja, os meios necessários para melhor realizar o desenvolvimento Humano.

Na orientação de Nussbaum, as capacidades são tratadas como sinônimo de direitos, levando a discussão para o campo dos direitos fundamentais, cuja compatibilidade com a dignidade da pessoa humana depende do alcance de um nível mínimo de capacidades básicas, quais sejam: (i) vida: ser capaz de viver uma vida de duração normal sem findá-la prematuramente nem antes que ela se torne tão diminuída

\footnotetext{
${ }^{2}$ Em tradução livre, adaptação razoável
} 
que não valha sua continuidade; (ii) saúde física: ser capaz de ter boa saúde, o que inclui saúde reprodutiva, receber boa alimentação e moradia adequada; (iii) integridade física: ser capaz de mover-se com liberdade de um lugar a outro, estar a salvo de qualquer violência, ter oportunidade de satisfação sexual e de opção de escolha para a reprodução; (iv) sentidos, imaginação e pensamento: usar os sentidos, as faculdades mentais, de forma "verdadeiramente humana" informada e desenvolvida por uma educação boa, capacidade e liberdade de experimentação, criação e escolha de obras e eventos, ter a garantia da liberdade de expressão política, artística, religiosa e ter capacidade de desfrutar prazeres, e possibilidade de evitar dores não benéficas; (v) emoções: desenvolver relações afetivas com outras pessoas e coisas, ser capaz de amar, de sentir saudades, de sentir gratidão e raiva, desenvolver-se emocionalmente de forma plena sem receio nem ansiedade; (vi) razão prática: ser capaz de conceber o bem e planejar a vida de forma crítica, com liberdade de consciência e crença; (vii) afiliação: viver com os outros, inteirar-se na sociedade, mostrar preocupação com os demais, ser capaz de se colocar no lugar do outro, não aceitar humilhações, autorrespeitar-se, alcançar um trabalho digno, estar a salvo de discriminação de qualquer natureza; (viii) outras espécies: viver respeitosamente e de forma próxima com outros componentes da biodiversidade e com o ambiente natural; (ix) lazer: usufruir de atividades recreativas, brincadeiras, diversões; $(x)$ controle sobre o próprio ambiente político e material: controlar o ambiente político, pelo direito a escolhas políticas da própria vida, participando da política, estando sob proteção da liberdade de expressão e de associação, ter direitos de propriedade, concorrer à vaga de emprego em igualdade com os demais, ter garantia de proteção contra busca e apreensão injustificados, trabalhar como ser humano, participar de relações significativas que permitam ser reconhecido e reconhecer os demais trabalhadores (NUSBAUMM, 2013, p. 91-93).

Em razão dos fins políticos da lista de capacidades, que pode vir a ser a base principiológica dos Estados, figurando como objetivos gerais nas suas constituições, para proporcionar uma vida minimamente digna aos cidadãos, desde que não ocorra nenhuma diminuição das capacidades, porque, apesar de qualitativamente distintas, todas são essenciais, não havendo sequer a possibilidade de promover uma para justificar a carência de outra, pois a ausência de uma das capacidades implica indignidade da pessoa humana (NUSBAUMM, 2013, p. 91-93).

Desse modo, a abordagem das capacidades de Nussbaum seria uma abordagem de direitos humanos, hábil a fundamentar acordos sociais, nos moldes dos acordos internacionais sobre direitos humanos, a fim de resolver as questões de justiça social não abordadas pela teoria do contrato social (NUSBAUMM, 2013, p. 13-14), uma vez que as fronteiras da justiça mostram os pontos frágeis do contratualismo, começando pela ideia do abandono do estado de natureza para a associação das partes para o alcance de vantagens mútuas, movidas somente por seus interesses individuais (NUSBAUMM, 2013, p. 192).

Ao afastar as pessoas com deficiência formação do contrato, este grupo não 
participará da definição dos princípios sociais básicos, e, consequentemente, não figurará entre os destinatários dos princípios escolhidos, uma vez que suas necessidades não foram observadas, as questões de justiça que lhes respeitam não foram postas em discussão (NUSBAUMM, 2013, p. 18-22, passim), porque contribuiriam menos e exigiriam mais (NUSBAUMM, 20 13, p. 127-130), uma vez que a tradição prefere unir pessoas ditas "normais" com potencialidade de cooperar em igualdade de condições (NUSBAUMM, 2013, p. |46-148).

Apesar de excluídos na formação do contrato social, os temas ligados às pessoas com deficiências figuraram na abordagem das capacidades de Nussbaum, que se diferencia da tradição do contrato social pelo tratamento substantivo a deficiência pela concepção de ação justa, como uma das motivações para a cooperação.

Uma abordagem de justiça mais adequada deve reconhecer a igualdade da cidadania das pessoas com deficiência e apoiar o desenvolvimento de atividades para sua inclusão social. O tratamento justo para as pessoas com deficiência exige novos arranjos sociais, que lhes permitam uma integração social, sem que haja algum tipo de estigmatização, proporcionando o acesso a todas as capacidades (NUSBAUMM, 20 I 3, p. I 2 I - 123).

Por sua vez, a abordagem das capacidades pode vir a servir para a construção de uma estrutura de direitos das pessoas com deficiência, a qual possibilite a reafirmação das suas capacidades por meio de prestações sociais, assistência e cuidado. Todavia, ela não é uma teoria inclusiva, por deixar de lado as formas mais severas de deficiência mental (NUSBAUMM, 2013, p. 187).

Dessa forma, a teoria articulada por Nusbaum consistiria numa teoria parcial de justiça social, uma vez que a igualdade das capacidades básicas seria o mínimo exigível para garantir a dignidade da pessoa humana.

\section{DA ABORDAGEM DE CAPACIDADES AOS DIREITOS FUNDAMENTAIS DA PESSOA COMDEFICIÊNCIA}

Nas últimas décadas, buscou-se proteger as pessoas com deficiência, por meio de ações que se assemelham à abordagem de capacidades, visto que tradicionalmente se identificou a deficiência como a existência de deficiências físicas, sensoriais, mentais ou intelectuais que limitam as atividades diárias, desviando-se de um padrão de normalidade que dificulta ou impossibilita a integração social das pessoas com deficiência. Esse modelo médico tem como característica a ideia de deficiência como uma patologia, que seria a única causa das limitações ou dificuldade experimentadas pela pessoa com deficiência.

Em consequência desse conceito medicalizado, a deficiência foi reduzida a um desvio da normalidade, passível de correção ou de cura, abreviando as demandas das pessoas com deficiência àquelas relacionadas a intervenções de saúde, de maneira a excluir o acesso a direitos sociais, ao "impor uma presunção de inferioridade biológica ou fisiológica as pessoas com deficiência, destacando a ausência de funcionalidades, 
contribuindo para um modelo de dependência". (PALACYOS, 2008, p. 174).

No ordenamento jurídico brasileiro, esse conceito puramente sanitário encontrou seu lugar no art. $3^{\circ}$ do Decreto n 3.298, de 1989, que definiu deficiência como "toda perda ou anormalidade de uma estrutura ou função psicológica, fisiológica ou anatômica que gere incapacidade para o desempenho de atividade, dentro do padrão considerado normal para o ser humano", ao regulamentar a Lei n 7.853, de 1989.

Essa compreensão unilateral tem sido sistematicamente criticada, uma vez que a "medicina retrata a deficiência de forma tendenciosa, que leva a práticas e arranjos sociais que oprimem as pessoas com deficiências; uma vez que as intervenções visam unicamente o indivíduo 'anormal' enquanto o meio ambiente é deixado intacto". ${ }^{3}$ (KRISTIANSEN; VEHMAS; SHAKESPEARE, p. 2).

Assim, de uma concepção fundada unicamente em um prisma biomédico, que considerava a pessoa com deficiência como alguém doente, fragilizado, carente de assistência; o conceito de deficiência passou a ser fundado em aspectos sociais, ultrapassando uma mera subsunção a padrões clínicos de um corpo considerado normal. (DINIZ; BARBOSA; SANTOS, 2009, p. 65).

A recepção do modelo social de deficiência, a partir da Convenção sobre os Direitos das Pessoas com Deficiência (CPCD), aprovada na Assembleia Geral das Nações Unidas (ONU), em 2006, levou a uma notável transformação, não só da nomenclatura utilizada para designar as pessoas com deficiência, mas do próprio conceito de deficiência, uma vez que o pressuposto do modelo social é considerar a deficiência o resultado da interação entre as características corporais do indivíduo e as barreiras e impedimentos da sociedade em que ele vive, ou seja, da combinação das limitações impostas pelo corpo deficiente a uma organização social pouco sensível a experiências das pessoas com deficiência.

Assim, o modelo social compreende uma expressão da diversidade humana, ou seja, pessoa com deficiência é aquela com impedimentos de ordem física, intelectual ou sensorial. Para esse segmento, não são os empecilhos naturais que geram a desigualdade, mas sim as barreiras impostas pela sociedade (DINIZ; BARBOSA; SANTOS, 2009, p. 69), haja vista que a deficiência é resultado de uma interação complexa entre pessoas e sociedade. Em uma comunidade hostil às diversidades corporais, uma pessoa com restrições leves de habilidades pode apresentar uma deficiência severa. Entretanto, se essa mesma pessoa for inserida em um meio receptivo às distinções poderá não experimentar a deficiência (DINIZ; SQUINCA; MEDEIROS,

\footnotetext{
${ }^{3} \mathrm{O}$ original em língua inglesa: "It has been argued that medicine portrays disability in a biased manner that leads to practices and social arrangements that oppress people with impairments; interventions are aimed solely at the 'abnormal' individual while the surrounding environment is left intact".
} 
2007, p. 3).

Esse modelo de abordagem da deficiência oferece novos instrumentos para a transformação social e a garantia de direitos das pessoas com deficiência. Sob essa perspectiva, a desigualdade desloca-se do corpo com deficiência para se instalar nas estruturas sociais. Fragiliza-se a ideia de recursos curativos e corretivos do modelo biomédico como única alternativa de bem-estar da pessoa com deficiência ao tempo em que se abrem possibilidades analíticas para a rediscussão do sentido de se habitar um corpo com limitações (DINIZ; BARBOSA; SANTOS, 2009, p. 69).

Atualmente, o modelo social coaduna com a concepção contemporânea de direitos humanos, cuja premissa é a proteção integral da pessoa e sua dignidade. A partir do pressuposto de que toda vida humana é digna, o modelo social argumenta que ressocialização está intimamente relacionada à inclusão e aceitação da diferença (PALACIOS, 2008, p. 104). Assim, o sujeito com deficiência não é definido apenas como destinatário de programas de saúde, mas sim como sujeito de direitos humanos. Isso significa que "las soluciones frente a la situación de vantaja de las personas com discapacidad se plantearían a partir del respeto a lós valores esenciales que son el fundamento de los derechos humanos. Es decir: dignidad, igualdad, solidariedad y libertad." (PALACIOS, 2004, p. 190) ${ }^{4}$.

Como uma questão de direitos humanos, os impedimentos naturais da pessoa com deficiência não podem simplesmente implicar uma segregação de qualquer natureza. Muito pelo contrário, as restrições de habilidade se apresentam como uma diversidade da natureza humana. Nesse sentido, caberia à sociedade promover um ambiente receptivo às pessoas com impedimentos. Ao tempo em que competirá ao Estado articular políticas públicas e mecanismos necessários para a participação social, política e econômica da pessoa com deficiência.

O preâmbulo da convenção, de forma abrangente, destaca que "a deficiência é um conceito em evolução", facilmente observada no ordenamento brasileiro, no antigo art. $3^{\circ}$ do Código Civil ${ }^{5}$, que qualificava toda pessoa com enfermidade ou deficiência mental como incapaz, para a conceituação presente na Lei Brasileira de Inclusão (LBI), que considera "pessoa com deficiência aquela que tem impedimento de longo prazo de natureza física, mental, intelectual ou sensorial, o qual, em interação com uma ou mais barreiras, pode obstruir sua participação plena e efetiva na sociedade em igualdade de

${ }^{4} O$ trecho correspondente na tradução é: "as soluções para a situação das pessoas com deficiência surgiriam do respeito pelos valores fundamentais, que são a base dos direitos humanos. Ou seja, a dignidade, a igualdade, solidariedade e liberdade"

${ }^{5}$ Redação anterior à vigência da Lei Brasileira de Inclusão, que, dentre tantas modificações, alterou a redação do art. $3^{\circ}$ do Código Civil de 2002, excluindo termos considerados discriminatórios da redação da norma.

${ }^{6}$ Art. $2^{\circ}$ da Lein ${ }^{\circ} 13.146$, de 2015. 
condições com as demais pessoas" .

Logo, torna-se primordial ilustrar o conceito atual de deficiência, posto não se tratar de mera teoria, uma vez que o legislador procurou estabelecer medidas contra a discriminação, além de orientar a implementação de políticas públicas afirmativas, dirigidas para as pessoas com deficiência.

Contrariando esta idéia, a Convenção sobre os Direitos da Pessoa com Deficiência afirma que a deficiência resulta dos "impedimentos de longo prazo de natureza física, mental, intelectual ou sensorial, os quais, em interação com diversas barreiras, podem obstruir sua participação plena e efetiva na sociedade em igualdades de condições com as demais pessoas". Fica muito clara a mudança de paradigma, já que o fator limitador da participação plena na sociedade não é mais a deficiência da pessoa, mas as atitudes e barreiras no seu entorno.

Uma leitura desatenta sugere um desacordo entre a descrição de deficiência apresentada no preâmbulo e a definição de pessoa com deficiência contida no artigo I da Convenção sobre os Direitos da Pessoa com Deficiência, ${ }^{7}$ mas uma leitura conjunta permite a reconstrução do conceito de deficiência da convenção (PALACIOS, 2008, p. 3 14-330), pois ambos destacam como elemento integrante a deficiência em si, bem como as barreiras que dificultem ou impeçam a participação plena da pessoa com deficiência.

Obviamente, é imprescindível a concordância de ambos os elementos; entretanto, o mais importante seria a existência de barreiras impeditivas à plena participação social, que, sem dúvidas, é o que dá relevância jurídica ao conceito de deficiência, visto que o propósito principal da Convenção sobre os Direitos da Pessoa com Deficiência é remover esses obstáculos a fim de "assegurar o exercício pleno e equitativo de todos os direitos humanos e liberdades fundamentais por todas as pessoas com deficiência”. Desse modo, quaisquer disfuncionalidades não associadas à existência de alguma barreira não pode ser considerada deficiência.

Também é relevante a simultaneidade desses elementos, pois se houver obstáculos que impeçam a plena participação social relacionados a outras razões que não a deficiência, estar-se-á diante de outro tipo de desigualdade e exclusão social. Não obstante, o conceito de deficiência deve ser interpretado da forma mais ampla possível, sob qualquer condição física, intelectual, mental ou sensorial, nos termos do artigo $1^{\circ} \mathrm{da}$

${ }^{7}$ Decreto n 6.949, de 2009, "Artigo I - [...] Pessoas com deficiência são aquelas que têm impedimentos de longo prazo de natureza física, mental, intelectual ou sensorial, os quais, em interação com diversas barreiras, podem obstruir sua participação plena e efetiva na sociedade em igualdades de condições com as demais pessoas".

${ }^{8}$ Artigo I do Decreto n 6.949 , de 2009. 
Convenção sobre os Direitos da Pessoa com Deficiência.

Assim, à luz dessas considerações, a partir da Convenção, poder-se-ia definir deficiência como uma situação caracterizada pela existência de barreiras para uma plena participação social de uma pessoa, relacionadas com o fato de ela apresentar algum tipo de deficiência, seja física, mental, intelectual ou sensorial. Portanto, as pessoas com deficiência seriam aquelas que enfrentam obstáculos para sua plena participação social, em relação à sua condição de deficiente.

Ainda, é oportuno ressaltar que a definição de deficiência proposta é um conceito valorativo, ou seja, exige um juízo de valor para determinar, no caso concreto, a condição de deficiente. As definições próprias do conceito médico eram descritivas, nas quais cabia apenas a constatação da existência de uma deficiência relevante, por meio de um diagnóstico clínico. Com o novo conceito de deficiência, o diagnóstico médico não é mais suficiente, talvez nem mesmo tão relevante, pois o que se torna relevante é a existência de obstáculos ou barreiras à participação social plena em razão de alguma deficiência.

\section{CONCLUSÃO}

Nas últimas décadas, importantes mudanças ocorreram em relação às pessoas com deficiência, especialmente no que concerne àquelas com impedimentos psíquicos ou intelectuais. As transformações ocorridas na realidade desses sujeitos ocorreram nas mais diversas áreas, a exemplo do tratamento psiquiátrico, que passou a ser pautado na dignidade da pessoa humana, da criação das políticas públicas de inclusão das pessoas com deficiência e do reconhecimento da capacidade legal desses sujeitos.

As abordagens da deficiência também acompanharam a evolução do reconhecimento dos direitos das pessoas com impedimentos. Assim, o modelo de prescindência que considerava a pessoa com deficiência como desnecessária para o desenvolvimento da sociedade, tornou-se insuficiente e evoluiu para o modelo social que considera a deficiência como uma questão de direitos humanos, e a define como uma associação de um corpo com limitações e barreiras sociais impostas a esses indivíduos.

No campo do Direito, essas mutações foram acompanhadas pelos documentos internacionais, que, ao longo das décadas, moldou a realidade jurídica das pessoas com deficiência, tanto no âmbito nacional quanto internacional. Esses tratados internacionais foram responsáveis por redefinir o modelo do tratamento psiquiátrico e a capacidade legal das pessoas com deficiência. Dentre eles, destaca-se a Convenção da Organização das Nações Unidas sobre os direitos das pessoas com deficiência que, por meio de uma abordagem multidisciplinar, interpreta a deficiência sob o modelo social ao tempo em que define como propósitos de promover, proteger e assegurar o exercício pleno e equitativo de todos os direitos humanos e liberdades fundamentais por todas as pessoas com deficiência e a promoção do respeito pela sua dignidade inerente.

De tudo o que se viu, pode-se dizer que a abordagem das capacidades é uma teoria 
que valoriza a diversidade humana, fundamentada nas reivindicações de justiça para todas as pessoas, especialmente aquelas que não estão enquadradas nos ditos padrões de normalidade. A teoria de Nussbaum rejeita a tese de que o fim da associação humana seria a obtenção de vantagem mútua e afastando a ideia de que a produtividade deve ser moeda de troca para o alcance dos padrões de uma vida digna. Prima pelas ações que venham promover os direitos desses grupos e conclama que os governos sejam obrigados a promover as capacidades essenciais de seus cidadãos, em limites condizentes com a dignidade humana, não admitindo que haja excluídos e discriminados, especialmente no que toca aos muitos desfavorecidos sociais. Assim, Nussbaum proclama a inclusão das pessoas com deficiência em todas as deliberações sobre as instituições básicas da sociedade, principalmente nas decisões que lhes dizem respeito, para deixá-los na posição original dos contratantes do pacto social.

\section{REFERÊNCIAS}

ASSEMBLEIA GERAL DAS NAÇÕES UNIDAS. Convenção sobre a eliminação de todas as formas de discriminação contra a mulher. 1979.

. Convenção sobre os direitos das crianças. 1989.

. Convenção sobre os direitos das pessoas com deficiência. 2006.

.Declaração universal dos direitos dos homens. 1948.

BRASIL. Decreto No 3.298, de 20 de dezembro de 1999. Disponível em: <http://www.planalto.gov.br/ccivil_03/decreto/d3298.htm>. Acesso em II abr. 2017.

. Decreto $N^{\circ}$ 6.949, de 25 de agosto de 2009. Disponível em: < http://www.planalto.gov.br/ccivil_03/_ato2007-20 10/2009/decreto/d6949.htm > . Acesso em I | abr. 2017.

. Lei $N^{0} 7.583$, de 24 de outubro de 1989. Disponível em: <http://www.planalto.gov.br/ccivil_03/leis/L7853.htm>. Acesso em I I abr. 2017.

. Lei $N^{\circ}$ 10.406, de 10 de janeiro de 2002. Disponível em: <http://www.planalto.gov.br/ccivil_03/leis/2002/L10406.htm>. Acesso em I I abr. 2017.

. Lei $N^{\circ}$ 13.146, de 06 de julho de 2015. Disponível em: <http://www.planalto.gov.br/ccivil_03/_ato20 I5-20 I8/20 I5/lei/l|3 | 46.htm>. 
Acesso em I I abr. 2017.

CONFERÊNCIA MUNDIAL SOBRE OS DIREITOS DOS HOMENS. Declaração de Viena e Programa de Ação. 1993.

DINIZ, Débora; BARBOSA, Lívia; SANTOS, Wederson Rufino dos. Deficiência, direitos humanos e justiça. Sur - Revista Internacional de Direitos Humanos, São Paulo, v. 5, p. 65- 77, 2009.

DINIZ, Débora; SQUINCA, Flávia; MEDEIROS, Marcelo. Deficiência, cuidado e justiça distributiva. Série Anis, Brasília, n. 48, p. I-6, 2007.

FOHRMANN, Ana Paula Barbosa. A Dignidade da Pessoa Humana no Direito Constitucional Alemão. Rio de Janeiro: Lumen lures, 2012.

INSTITUTO BRASILEIRO DE GEOGRAFIA E ESTATÍ́STICA. Pesquisa nacional de saúde 20 I3. Rio de Janeiro: IBGE, 2013.

KRISTIANSEN, Kristjana; VEHMAS, Simo; SHAKESPEARE. Tom (org.) et al. Arguing about disability: philosophical perspectives. London: Routledge, 2009.

NUSBAUMM, Martha. Fronteiras da justiça: deficiência, nacionalidade, pertencimento à espécie. São Paulo: Martins Fontes, 2013.

ONU. World Health Organization. World report on desabilities. Geneve. WHO Publications, 201 I.

PALACIOS, Augustina. El derecho a la igualdad de las personas com discapacidad y La obligación de realizar ajustes razonables. In: CERVERA, Ignacio Campoy (Org.). Los derechos de lãs personas com discapacidad: perspectivas sociales, políticas, jurídicas y filosóficas. Madrid: Dykinson, 2004.

. El modelo social de discapacidad: orígenes, caracterización y plasmación en la Convención Internacional sobre los Derechos de las Personas com Discapacidad Madrid: Cinca, 2008.

PIOVESAN, Flávia. Convenção da ONU sobre os Direitos das Pessoas com Deficiência: inovações, alcance e impacto. In: FERRAZ, Carolina Valença et al. (Coord.). Manual dos direitos das pessoas com deficiência. São Paulo: Saraiva, 2012. 
Direitos humanos e justiça internacional: um estudo comparativo dos sistemas regionais europeu, interamericano e africano. São Paulo: Saraiva, 2006.

. Direitos humanos e o direito constitucional internacional. 7. ed., rev., ampl. e atual. São Paulo: Saraiva, 2006.

ROSATO, Cássia Maria; CORREIA, Ludmila Cerqueira. Caso Damião Ximenes Lopes: mudanças e desafios após a primeira condenação do Brasil pela Corte Interamericana de Direitos Humanos. Sur - Revista Internacional de Direitos Humanos, São Paulo, v. 15,2012 .

SARLET, Ingo Wolfgang. Dignidade da pessoa humana e direitos fundamentais na Constituição Federal de 1988. 3. ed. atual. e ampl. Porto Alegre: Livraria do Advogado, 2004

SEN, Amartya. A ideia de justiça. São Paulo: Companhia das Letras, 201 I .

Recebido em: 07/06/2017

Aprovado em: 26/07/2017 